\title{
THE DEVIOUS PATH OF SLOW WORK
}

\author{
GRACE E. BIRD
}

R. I. College of Education and R. I. State College

Only recently have teachers come to realize that accuracy is not conditioned by slow work. A class experiment in adding made by Thorndike ${ }^{1}$ and extending through several years indicates that a very close relationship exists between rapidity and accuracy. Among six-hundred seventy-one students variations were considerable, but the quickest sixty-five averaged one hundred additions per one hundred seconds. The slowest averaged only one-fourth as many. The sixtyfive individuals who added the most rapidly made seven errors per thousand additions. The twenty who were slowest made an average of seventeen and one-half errors. Similar relationship is shown throughout the intermediate speed groups, and is permanently characteristic there also.

Through practice one hits upon short cuts or "kinks" as they are called by the industrial worker, thereby eliminating superfluous motions and varying factors, - hence the improvement in speed that comes through practice. According to Gilbreth, ${ }^{2}$ however, fast motions are different in character from slow motions. The learner, therefore, should be encouraged to attain standard speed of motions as early as possible. If these motions are such as cannot be made by the beginner at standard speed, rapidity should approach as nearly as possible that used by the expert. Otherwise the habit may be initiated incorrectly. Also, the worker in seeking speed later may find that the different motions may cause retroactive inhibition, as in other interfering habits, not well-automatized. Jesperson, the Danish philologist found the rate for optimum initial speed in teaching languages, also to agree with these conclusions. In industrial practice the learner may be encouraged to approximate standard speed by giving him work in which the finest quality is not essential. Eventually, accuracy of method and speed occur simultaneously with good quality. In other words, if the method and the speed are taken care of, the quality will take care of itself.

By standard speed is meant not always high speed, but that rate of speed which will produce the best results efficiently. Undue haste

1 Thorndike, E. L.: Relation Between Speed and Accuracy in Addition. Jour. Ed. Psych., Vol. 5.

'Gilbreth, F. B. \& L. M.: "Applied Motion Study," 1917, Chap. VI. 
is apt to arouse such emotions as anxiety, fear, or annoyance which invariably tend to interfere with rational processes. If, however, the child's work in arithmetic or any other subject requiring both speed and accuracy be properly focalized and motivated through play stimuli so that it will seem worth his while to exercise optimum effort, he may attain speed very early in the learning process. In arithmetic, approximations of the answer rather than finding the exact result give him an opportunity to attain initial speed in the same way that the industrial beginner may approach standard speed if given work in which the finest quality of workmanship is not essential.

Gilbreth, in learning to lay bricks, observed that his teacher employed three sets of motions to do the same thing. One was the demonstrating set used for teaching, the other two were employed in his own work, one being slow and the other fast. He used different motions when working slowly than when working rapidly because of the different muscle tension involved. In the latter instance centrifugal force, inertia, momentum, combination of motions, and play for position functioned favorably. When there was no emphasis on speed he was differently affected by these variables.

In mental processes, also, there is a difference between rapid adjustment and slow adjustment. The distinction may be realized by the most casual introspection. Although adding is a familiar process it is very complex. In order to add eight and nine on paper, for example, the individual first perceives visually the number eight, at the same time perhaps experiencing one or more images involving associations depending upon his apperceptive background. This process is repeated for the number nine and for the product seventeen. Furthermore the product may be almost subconsciously resolved into other element combinations such as ten and seven, five more than a dozen, etc. The act of writing the number may attract the writer's attention to that motor performance with its own complex elements. The longer one delays the completion of the act the larger the number of "irrelevant bonds" realized. In slow addition a person may even revert to wasteful habits of childhood such as counting on the fingers, lip movement, vocalization, etc. In rapid calculation learned through properly focalized practice, such irrelevant matters are crowded out through the exercise of inhibitory processes. The first perception of the numbers set off the automatic response of the product, with the elimination of useless and wasteful intermediate performances.

Recently one hundred college students were tested by the writer 
with slow and rapid adding of examples taken from the Courtis research tests. For two minutes the students were required to work as quickly as possible. The median number of errors was found to be three, the quartile deviation 0.5. The students were then asked to continue adding. This time they were cautioned to work slowly and accurately. The median number of errors was four, the quartile deviation 0.8. The workers were then requested to describe everything that entered their minds during the rapid adding. Only five individuals recorded conscious distractions of any kind. The others stated as their central thought a desire to get the answer, or to add as rapidly as they were supposed to. When required to record their thoughts as experienced during slow adding all but three mentioned distractions. These included variety of imagery, adding by combining units rather than by combining groups, consciously unnecessary repetitions of sums obtained in the process of adding a column, emotional disturbances, physical uneasiness, observation of environmental stimuli, halting uncertainties regarding the sum of certain numbers, forgetfulness of the sum already found, losing the place, slight amusement at the experiment, and fatigue.

If it were possible to draw accurate motion paths of these distractions the result would be a tangled skein as intricate as the motions of the slow industrial worker. If this vagrancy of attention occurs in individuals who have learned to add well enough to enjoy their skill, it should be even more evident in the case of the child who in the process of learning to add is only too ready to be diverted by outside stimuli from a difficult and irksome task in the stage when it is neither novel, nor yet pleasantly automatic. Continual shifts of attention to distractions might easily occasion the fatigue experienced by some of the individuals during the writer's experiment in addition. Further investigation might show decreased efficiency even more marked than the reduction of accuracy from a median of three errors to a median of four. The larger percentage of errors during slow adding and the variety of irrevelant mental content indicate that in some way the nature of the work is different from that of rapid adding.

In reading, also, if the by-paths of articulation, inner speech, eye and throat tensions, auditory, motorizing mechanisms, and imagery of the slow reader could be reproduced and compared with the direct route of the rapid reader, the relationship would no doubt parallel the comparison between slow and rapid adding.

In J. A. O'Brien's ${ }^{1}$ experiment, photographic records were made 
of the eye movements of ten pupils in grades III to VIII before and after training in silent reading. A study of the records showed that the improvement on the physiological side was effected chiefly by a lessening of the number of the fixation pauses rather than a decrease in the duration of these pauses. The development of speed was also accompanied by a marked decrease in the number of regressive movements and by the setting up of habits of regular rhythmical eyemovement. This adds evidence to the assumption that slow work is of a different character from quick work.

As has already been pointed out by M. A. Burgess, ${ }^{1}$ scales for the comparative attainment in reading measure quality, difficulty, or amount, though reading is not easily measured by scales for quality or scales for difficulty. It is measurable by scales for amount. It is probable that difficulty will be indirectly measured eventually through a series of carefully-graded tests for amount, thereby following the law of the single variable as recognized in scientific measurement. This single variable (amount) obviously involves speed.

In a previous experiment ${ }^{2}$ by the writer in giving standard tests to a whole school the highest correlations between tests occurred between comprehension and speed in Kansas Silent Reading and between speed and accuracy in Courtis arithmetic. In handwriting, however, a minus correlation was found between speed and legibility probably because the children had been trained to write slowly, and were therefore disturbed by the effort to inhibit superfluous motions. Rapid drill from the beginning focalizes and initiates habit with a minimum of waste.

"L'éxercice abrège le calcul, parce qu'il modifie le travail, non seulement au point de vue quantitatif, en accroissant la vitesse d'éxécution des opérations élémentaires et la vitesse de transition d'une opération à l'autre, mais et surtout au point de vue qualitatif, c'est à dire en transformant la nature du travail."

Pupils should think in terms of results more than in terms of the process. This economical method encourages speed and is more conducive to concentration because in less danger of distraction elements which tend to alter the character of the work.

Conclusion.-Fast motions are essentially different from slow motions not only in industrial but in intellectual work.

1 Twentieth Yearbook, Nat. Soc. for the St. of Ed., Pt. II.

${ }^{2}$ Bird, Grace E.: A Test of Some Standary Test. Jour. Ed. Psych., Vol. II, No. 5.

${ }^{3}$ Foucault, M.: L'Etude Scientifique du Travail Mental Specialement Dans le Travail d'Addition. L'Année Psychologique, Tome XX, p. 125. 